Int. J. Electrochem. Sci., 14 (2019) $7663-7672$

International Journal of

ELECTROCHEMICAL

SCIENCE

www.electrochemsci.org

\title{
Preparation of Three-Dimensional Graphene and Myoglobin Modified Electrode for Electrocatalysis of Trichloroacetic Acid
}

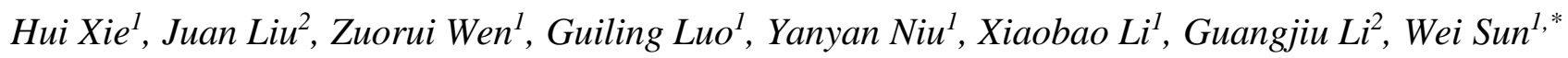 \\ ${ }^{1}$ Key Laboratory of Water Pollution Treatment and Resource Reuse of Hainan Province, Key \\ Laboratory of Functional Materials and Photoelectrochemistry of Haikou, College of Chemistry and \\ Chemical Engineering, Hainan Normal University, Haikou 571158, P R China \\ ${ }^{2}$ Key Laboratory of Optic-electric Sensing and Analytical Chemistry for Life Science of Ministry of \\ Education, College of Chemistry and Molecular Engineering, Qingdao University of Science and \\ Technology, Qingdao 266042, P R China \\ *E-mail: swyy26@ hotmail.com \\ Key Laboratory of Water Pollution Treatment and Resource Reuse of Hainan Province
}

doi: $10.20964 / 2019.08 .40$

Received: 16 March 2019 / Accepted: 21 May 2019 / Published: 30 June 2019

In this paper three-dimensional graphene (3DGR) was synthesized by hydrothermal method and further used as electrode modifier on the surface of carbon ionic liquid electrode (CILE). Then an electrochemical biosensor was prepared by further immobilizing myoglobin (Mb) and chitosan (CTS) on the electrode surface in sequence. Spectral results showed that Mb immobilized with 3DGR maintained its original structure. Cyclic voltammogram of CTS/Mb/3DGR/CILE in $\mathrm{pH} 4.0$ phosphate buffer solution gave a pair of quasi-reversible redox peak, indicating that direct electrochemistry of $\mathrm{Mb}$ had been achieved on the electrode, which was attributed to the specific macrostructure of 3DGR with high conductivity and large interconnected network. By using CTS/Mb/3DGR/CILE as the working electrode, a third-generation electrochemical biosensor was constructed for the detection of trichloroacetic acid with the linear range from 16.0 to $80.0 \mathrm{mmol} / \mathrm{L}$ and the detection limits calculated as $5.33 \mathrm{mmol} / \mathrm{L}$. Experimental results extended the application of 3DGR in the electrode modification with advantages such as high sensitivity, wide detection range, good stability and reproducibility.

Keywords: carbon ionic liquid electrode, three-dimensional graphene, myoglobin, electrochemistry, trichloroacetic acid

\section{$\underline{\text { FULL TEXT }}$}

(C) 2019 The Authors. Published by ESG (www.electrochemsci.org). This article is an open access article distributed under the terms and conditions of the Creative Commons Attribution license (http://creativecommons.org/licenses/by/4.0/). 